\title{
Tumor Volume Reduction Rate to Induction Chemotherapy Is a Prognostic Factor for Locally Advanced Head and Neck Squamous Cell Carcinoma: a Retrospective Cohort Study
}

\section{Chi-hsien Huang}

China Medical University Hospital https://orcid.org/0000-0002-8948-4827

Ting-Chun Lin

China Medical University Hospital

Ming-Yu Lien

China Medical University Hospital

\section{Fu-Ming Cheng}

China Medical University Hospital

\section{Kai-Chiun Li}

China Medical University Hospital

Chih-Yuan Lin

National Yang Ming Chiao Tung University

Ti-Hao Wang ( $\nabla$ thothwang@gmail.com)

China Medical University Hospital

\section{Research}

Keywords: Locally-advanced, head and neck cancer, squamous cell carcinoma, induction chemotherapy, early response, tumor volume, volume reduction, GTV

Posted Date: November 2nd, 2021

DOI: https://doi.org/10.21203/rs.3.rs-993291/v1

License: (c) (i) This work is licensed under a Creative Commons Attribution 4.0 International License. Read Full License 


\section{Abstract}

\section{Background}

Aim of this study was to evaluate the prognostic of tumor volume reduction rate (TVRR) status post induction chemotherapy (IC) in LA-HNSCC.

\section{Methods}

Patients with newly diagnosed LA-HNSCC from year 2007 to 2016 at a single center were included in this retrospective study. All patients had received IC as TPF (taxotere, platinum, fluorouracil) followed by daily definitive intensity-modulated radiotherapy (IMRT) for $70 \mathrm{~Gy}$ in 35 fractions concurrent with or without cisplatin-based chemotherapy. Tumor volume reduction rate of the primary tumor (TVRR-T) and lymph node (TVRR-N) was measured and calculated by contrast-enhanced CT images at diagnosis, and one month after final IC cycle, and analyzed though a univariate and multivariate Cox regression model.

\section{Results}

Ninety patients of the primary cancer sites at hypopharynx (31/90, 34.4\%), oropharynx $(29 / 90,32.2 \%)$, oral cavity $(19 / 90,21.1 \%)$ and larynx $(11 / 90,12.2 \%)$ were included in this study, with a median follow-up time interval of 3.9 years. In univariate Cox regression analysis, the TVRR-T as the only variable showed a significant difference for disease-free survival (DFS) (hazard ratio [HR] 0.77, 95\% confidence interval (Cl) 0.63 to $0.96 ; P=0.02$ ), aside from cancer site, RECIST, age and IC dose. In multivariate Cox regression analysis, The TVRR-T was also an independently significant prognostic factor for DFS (HR $0.77,95 \% \mathrm{Cl}$ 0.62 to $0.97 ; P=0.02$ ). At a cutoff value using TVRR-T of $50 \%$ in Kaplan-Meier survival analysis, the DFS was significant higher with TVRR-T $\geq 50 \%$ group (log-rank test, $p=0.024$ ), and also a trend of improved OS. (log-rank test, $p=0.069$ ).

\section{Conclusions}

TVRR-T was related to improved DFS and trend of improved OS. Other factors including patient's age at diagnosis, the primary cancer site, and RECIST, were not significantly related to DFS.

\section{Background}

In the past two decades, induction chemotherapy (IC) has become a common treatment modality for locally-advanced head and neck squamous cell carcinoma (LA-HNSCC). There are at least four large phase III randomized trials investigated the benefits and induction chemotherapy.[1-4] The general conclusion of these trials was that IC may lower distant failure rates in LA-HNSCC without improving overall survival. For laryngeal and hypopharyngeal cancer, there is an additional benefit with applying IC as a tool for selecting candidates for organ preservation [5-7]. However, for head and neck primary cancer sites other than larynx and hypopharynx, IC did not offer a clear benefit for either the organ preservation rate or survival. 
The assessment of tumor response in organ preservation studies varied by using laryngoscope or images with unidimensional (in GORTEC 2001-01, and VALCSG trial) or bidimensional (using WHO in EORTC 24891) measurements.[8-10] Although widely used to describe the regression status of a solid tumor, unidimensional measurement, such as RECIST, was not always a predictive value for the treatment outcome of head and neck cancer patients.[11]

On contrary, the extent of tumor volume shrinkage after IC have been established as a prognostic factor for other cancer. In rectal cancer, preoperative tumor volume reduction after chemoradiation therapy predict disease free survival.[12] Tumor volume reduction rate (TVRR) during adaptive radiation therapy is regarded as a prognosticator for PFS in nasopharyngeal cancer.[13] In LA-HNSCC, with primary tumor volume being a predictive measurement of local control with chemoradiation, by similar justification, post-IC tumor volume reduction has potential for predicting the outcome, which has not yet been investigated.[14]

In this study, we discussed the characteristics and the prognostic value of tumor volume reduction rate (TVRR) status post IC in LA-HNSCC patients. We also argue that TVRR is a suitable prognostic indicator for following definitive treatment outcome for LA-HNSCC.

\section{Methods}

\section{Patient cohort and clinical data collection}

We retrospectively collected the clinical and imaging data of patients with newly diagnosed LA-HNSCC from year 2007 to 2016 at a single center (China Medical University Hospital, Taichung, Taiwan). Patients receiving primary treatment of IC followed by definitive (chemo-)radiotherapy (CRT) were included in the study cohort. The inclusion criteria for the retrospective analysis were as follows: (1) The patient's age was 20 to 75 years old. (2) The newly diagnosed HNSCC with pathological proof (3) There was no distant metastasis at diagnosis. (4) The patient had no prior history of any other cancer. (5) Contrast-enhanced CT scans were performed at diagnosis and one month after final cycle of IC (defined as interim CT). (6) The patient received at least one cycle of IC. (7) The patient received at least one course of defintive (C)RT.

We collected data including patient's age, gender, TNM classification, primary site of the cancer, smoking status, disease status, pattern of recurrence, time of recurrence and death. We also measured the response of tumor volume by RECIST 1.1[15], verified by two board certified hemato-oncologists one month after final cycle of IC. The overall survival (OS) duration was defined as the time interval between the date of diagnosis and the date of death or the last follow-up visit date. The disease-free survival (DFS) was defined as the time interval between the date of diagnosis and the date of any disease recurrence (including distant metastasis and local recurrence) or the last follow-up visit date. Data collection and analysis were approved by the institutional review board of the hospital (CMUH106-REC3119). 


\section{Treatment Schedule in Our Facility}

IC followed a dose-dense TPF (ddTPF) protocol[16] with cisplatin $50 \mathrm{mg} / \mathrm{m}^{2}$ and docetaxel $50 \mathrm{mg} / \mathrm{m}^{2}$ on day 1 , leucovorin $250 \mathrm{mg} / \mathrm{m}^{2}$ on day1, followed by 48 -h continuous infusion of $2500 \mathrm{mg} / \mathrm{m}^{2}$ of 5 fluorouracil on day 1 and 2, every 2 weeks. Daily definitive IMRT for 68.4 to 72 Gy with 1.8 to $2.0 \mathrm{~Gy}$ fraction size was given alone or concurrent with chemotherapy (CCRT) with weekly cisplatin for 35-40 $\mathrm{mg} / \mathrm{m}^{2}$.

\section{Delineation of anatomic tumor volume on CT image}

For each patient, the tumor was contoured by a senior resident and verified by a board-certified radiation oncologist, based on the contrast-enhanced CT images both at diagnosis and interim. The volumes of the primary tumor and the involved neck lymph nodes were separately delineated. The gross tumor volume of the primary tumor and the involved nodes before IC were designated as GTV-T1 and GTV-N1. (as shown in Figure 1A) On interim CT, primary tumor and the involved nodes before IC were designated as GTV-T2 and GTV-N2. (Figure 1B) The tumor volume reduction rate of primary tumor (TVRR-T) was calculated as $(\mathrm{GTV}-\mathrm{T} 1-\mathrm{GTV}-\mathrm{T} 2) / \mathrm{GTV}-\mathrm{T} 1$, whereas nodal volume reduction rate $(\mathrm{TVRR}-\mathrm{N})=(\mathrm{GTV}-\mathrm{N} 1-\mathrm{GTV}-\mathrm{N} 2) / \mathrm{GTV}-$ N1.

\section{Statistical analysis}

Data were analyzed using Python 3.6.4 scipy and lifelines packages. Univariate and multivariate analyses using the Cox regression model were applied to distinguish significant prognostic factors. Survival curves were created under Kaplan-Meier product-limit methods, and comparison was done using the log-rank test. In subgroup analysis for different cancer sites and disease status, we used Kruskal-Wallis test for continuous variables and chi-squared test for categorical variables.

\section{Results}

\section{Patient and treatment characteristics}

A total of ninety patients were included for analysis. The median follow-up time interval was 3.9 years. Of the ninety patients, eighty-seven were stage IV and three were stage III (based on the seventh edition of AJCC staging). The primary cancer sites were hypopharynx (31/90, 34.4\%), oropharynx (29/90, 32.2\%), oral cavity $(19 / 90,21.1 \%)$ and larynx $(11 / 90,12.2 \%)$. Among the 29 oropharyngeal cancer patients, $13 / 29,44.8 \%$ had available p16 status. Of the 13 patients, only one patient $(1 / 13,7.7 \%)$ was p 16 -positive, and the other 12 patients $(12 / 13,92.3 \%)$ were p16-negative. (Table 1 ) 
Table 1

Patient characteristics of all 90 patients who received induction chemotherapy. *IQR, interquartile range; DM, distal metastasis; LR, locoregional recurrence; SP, second primary; TVRR tumor volume reduction

rate; TPF, docetaxel, cisplatin, and fluorouracil; GTVtotal1, pre-IC gross tumor volume of both tumor and nodal sites; GTVtotal2, post-IC gross tumor volume of both tumor and nodal sites.

\begin{tabular}{|ll|}
\hline Patient characteristics & All patients (percentage) \\
\hline $\mathbf{n}$ & 90 \\
\hline Age (median, [IQR]) & $53.5[49.2,61.0]$ \\
\hline Sex & \\
\hline F & $4(4.4)$ \\
\hline M & $86(95.6)$ \\
\hline T category & \\
\hline 1 & $2(2.2)$ \\
\hline 2 & $20(22.2)$ \\
\hline 3 & $17(18.9)$ \\
\hline 4A & $25(27.8)$ \\
\hline 4B & $26(28.9)$ \\
\hline N category & \\
\hline 0 & $11(12.2)$ \\
\hline 1 & $1(1.1)$ \\
\hline 2A & $1(1.1)$ \\
\hline 2B & $36(40.0)$ \\
\hline 2C & $36(40.0)$ \\
\hline S & $5(5.6)$ \\
\hline Primary site & $30(33.3)$ \\
\hline 4A & \\
\hline A & \\
\hline
\end{tabular}

\# there was no distal metastasis and locoregional recurrence combine 


\begin{tabular}{|ll|}
\hline Patient characteristics & All patients (percentage) \\
\hline Hypopharynx & $31(34.4)$ \\
\hline Larynx & $11(12.2)$ \\
\hline Oral cavity & $19(21.1)$ \\
\hline Oropharynx & $29(32.2)$ \\
\hline Primary site response to IC & \\
\hline (RECIST) & \\
\hline PR & $58(64.4)$ \\
\hline CR & $18(20.0)$ \\
\hline SD & $13(14.4)$ \\
\hline PD & $1(1.1)$ \\
\hline Follow-up days (median, [IQR]) & $1413.5[506.2,1951.5]$ \\
\hline GTVtotal1 (ml) (median, [IQR]) & $50.6[26.1,98.7]$ \\
\hline GTV-T1 & $29.8[14.4,76.5]$ \\
\hline GTV-N1 & $10.1[3.1,21.7]$ \\
\hline GTVtotal2 & $24.5[11.5,58.0]$ \\
\hline GTV-T2 & $17.1[7.2,40.1]$ \\
\hline GTV-N2 & $3.9[1.2,9.2]$ \\
\hline TVRR-total (\%) (median, [IQR]) & $46.1[29.8,60.1]$ \\
\hline TVRR-T (\%) & $43.6[24.3,54.3]$ \\
\hline TVRR-N (\%) & $53.3[31.6,66.3]$ \\
\hline Disease status to the latest follow-up date & \\
\hline Never disease free & $25(27.8)$ \\
\hline No recurrence & $38.0)$ \\
\hline Recurrence & \\
\hline Recur pattern & \\
\hline DM & \\
\hline LR & \\
\hline
\end{tabular}

\# there was no distal metastasis and locoregional recurrence combine 


\begin{tabular}{|ll|}
\hline Patient characteristics & All patients (percentage) \\
\hline SP & $8(22.9)$ \\
\hline IC duration (days) (median, [IQR]) & $74.0[57.0,80.8]$ \\
\hline TPF dosage (median, [IQR]) & $3.0[2.5,3.0]$ \\
\hline T dose $\left(\mathrm{mg} / \mathrm{m}^{2}\right)$ & $263.5[212.4,294.5]$ \\
\hline P dose $\left(\mathrm{mg} / \mathrm{m}^{2}\right)$ & $245.4[202.9,291.8]$ \\
\hline F dose $\left(\mathrm{mg} / \mathrm{m}^{2}\right)$ & $13116.8[10322.7,14503.7]$ \\
\hline Smoking & \\
\hline No & $10(11.9)$ \\
\hline Yes & $74(88.1)$ \\
\hline P16 & \\
\hline Negative & $12(92.3)$ \\
\hline Positive & $1(7.7)$ \\
\hline N/A & $77(86)$ \\
\hline Complete definitive treatment & $77(86)$ \\
\hline RT alone & $58(64)$ \\
\hline concurrent with cisplatin & $19(21)$ \\
\hline Incomplete definitive treatment & $13(14)$ \\
\hline RT alone & $10(11)$ \\
\hline concurrent with cisplatin & $3(4)$ \\
\hline \# there was no distal metastasis and locoregional recurrence combine \\
\hline
\end{tabular}

All patients have received IC: 85 patients $(85 / 90,94.4 \%)$ received ddTPF, and five patients $(5 / 90,5.6 \%)$ received alternative IC regimen consisting of carboplatin, methotrexate and/or cetuximab.

All patients have received curative intent daily IMRT dose for 68.4 to 72 Gy with 1.8 to 2.0 Gy fraction size: 77 patients $(77 / 90,85.6 \%)$ had complete RT treatment courses, in which 58 (58/77, 75\%) patients were RT alone and 19 (19/77, 25\%) patients were concurrent with weekly cisplatin; 13 patients (13/90, $14.4 \%$ ) had incomplete RT treatment courses (total dose below $68.4 \mathrm{~Gy}$, median dose $56 \mathrm{~Gy}$, IQR [38, 60]), in which $10(10 / 13,78 \%)$ patients were RT alone and $3(3 / 10,22 \%)$ patients were concurrent with weekly cisplatin. 
There are thirteen patients ( $n=13 / 90,14 \%)$ had incomplete definitive (C)RT courses, ranging from minimum 12 Gy to maximum $68 \mathrm{~Gy}$, median $56 \mathrm{~Gy}$ with interquartile range $38 \mathrm{~Gy}$ to $60 \mathrm{~Gy}$, and eight of them $(n=8 / 13,61.5 \%)$ failed to reach initial complete remission.

\section{Tumor volume response to induction chemotherapy}

The tumor volume of primary site GTV-T1 (at diagnosis) and GTV-T2 (at interim study) were median 29.8 (14.4-76.5, IQR) $\mathrm{ml}$ and 17.1 (7.2-40.1, IQR) $\mathrm{ml}$, and TVRR-T was median 43.6\% (24.3\%-54.3\%, IQR). Respectively, the nodal volume GTV-N1 and GTV-N2 were median 10.1 (3.1-21.7, IQR) $\mathrm{ml}$ and median 3.9 (1.2-9.2, IQR) ml. TVRR-N was median 53.3\% (31.6\%-66.3\%, IQR), distribution was shown (Figure 2A and 2B).

By RECIST criteria, tumor response comprised of partial response (PR) (58/90, 64.4\%), complete response (CR) $(18 / 90,20.0 \%)$, stable disease (SD) $(13 / 90,14.4 \%)$, and progressive disease (PD) $(1 / 90,1.1 \%)$.

There was only one patient had disease progression in primary tumor site. Four patients had disease progression on lymph node volume despite their primary site volume shrinking, in which three of them had nodal volume increasing over $10 \%$ and never reached disease free, even with two of them had received complete definitive RT.

\section{Different primary sites of cancer response to IC and outcome of definitive treatment}

In four types of cancers, TVRR-T showed a similarity across different primary sites, as well as their received dosage of $\mathrm{IC}$, despite the fact that oral cavity cancer had significant larger primary tumor volume both before and one month after IC, ie GTV-T1 $85.3 \mathrm{ml}(\mathrm{p}=0.01)$ and GTV-T2 $44.3(p=0.03)$.

Regarding response to definitive (C)RT, hypopharynx, larynx, and oropharynx have similar complete response rate of $51.6 \%, 45.5 \%$, and $44.8 \%$ respectively, the similar medians follow-up days of 1352,1606 , and 1698 , and the never free of disease percentage being $25.8 \%, 18.2 \%$, and $6.9 \%$. In contrary, oral cavity cancer responded significantly worse to definitive (C)RT, with $68.4 \%$ never free of disease, and only $21.1 \%$ reached complete remission. (as shown in Table 2). 
Table 2

Patient characteristics grouped by primary sites. ${ }^{*} \mathrm{QR}$, interquartile range; TVRR tumor volume reduction rate

\begin{tabular}{|c|c|c|c|c|c|}
\hline & Hypopharynx & Larynx & Oral cavity & Oropharynx & p-value \\
\hline $\mathrm{n}$ & 31 & 11 & 19 & 29 & \\
\hline \multicolumn{6}{|l|}{ T category } \\
\hline 1 & $2(6.5)$ & 0 & 0 & 0 & 0.085 \\
\hline 2 & 7 (22.6) & $4(36.4)$ & $2(10.5)$ & $7(24.1)$ & \\
\hline 3 & $9(29.0)$ & 0 & $1(5.3)$ & $7(24.1)$ & \\
\hline $4 \mathrm{~A}$ & $6(19.4)$ & $3(27.3)$ & $6(31.6)$ & $10(34.5)$ & \\
\hline 4B & $7(22.6)$ & $4(36.4)$ & $10(52.6)$ & $5(17.2)$ & \\
\hline \multicolumn{6}{|l|}{$\mathrm{N}$ category } \\
\hline 0 & $3(9.7)$ & $3(27.3)$ & $2(10.5)$ & $3(10.3)$ & 0.578 \\
\hline 1 & 0 & 0 & 0 & $1(3.4)$ & \\
\hline $2 A$ & 0 & 0 & 0 & $1(3.4)$ & \\
\hline $2 B$ & $15(48.4)$ & $3(27.3)$ & $6(31.6)$ & $12(41.4)$ & \\
\hline $2 C$ & $11(35.5)$ & 3 (27.3) & $10(52.6)$ & $12(41.4)$ & \\
\hline 3 & $2(6.5)$ & $2(18.2)$ & $1(5.3)$ & 0 & \\
\hline \multicolumn{6}{|l|}{ Stage } \\
\hline 3 & $1(3.2)$ & 0 & $1(5.3)$ & $1(3.4)$ & 0.108 \\
\hline $4 \mathrm{~A}$ & $21(67.7)$ & $6(54.5)$ & $7(36.8)$ & $23(79.3)$ & \\
\hline 4B & $9(29.0)$ & $5(45.5)$ & $11(57.9)$ & $5(17.2)$ & \\
\hline $\begin{array}{l}\text { Follow-up days } \\
\text { [IQR] }\end{array}$ & $\begin{array}{l}1352.0 \\
{[590.0,1943.0]}\end{array}$ & $\begin{array}{l}1606.0 \\
{[658.0,2019.5]}\end{array}$ & $\begin{array}{l}399.0 \\
{[336.5,1368.5]}\end{array}$ & $\begin{array}{l}1698.0 \\
{[1083.0,2018.0]}\end{array}$ & $0.019 *$ \\
\hline $\begin{array}{l}\text { GTV-T1 ml } \\
\text { (median, IQR) }\end{array}$ & $\begin{array}{l}15.7 \\
{[10.9,50.0]}\end{array}$ & $\begin{array}{l}29.9 \\
{[17.1,50.7]}\end{array}$ & $\begin{array}{l}85.3 \\
{[45.4,132.9]}\end{array}$ & $28.8[17.9,49.7]$ & $0.001 *$ \\
\hline $\begin{array}{l}\text { GTV-N1 } \\
\text { (median, IQR) }\end{array}$ & $8.2[3.7,16.9]$ & $12.6[1.1,37.2]$ & $11.0[3.5,22.8]$ & $11.8[2.8,21.8]$ & 0.953 \\
\hline $\begin{array}{l}\text { GTV-T2 } \\
\text { (median, IQR) }\end{array}$ & $9.1[5.5,26.4]$ & $19.8[8.4,33.4]$ & $\begin{array}{l}44.3 \\
{[21.5,92.8]}\end{array}$ & $14.2[8.0,25.7]$ & $0.003^{*}$ \\
\hline $\begin{array}{l}\text { GTV-N2 } \\
\text { (median, IQR) }\end{array}$ & $3.0[1.6,7.4]$ & $2.7[0.4,8.3]$ & $5.9[2.1,12.2]$ & $4.6[1.2,7.7]$ & 0.566 \\
\hline
\end{tabular}




\begin{tabular}{|c|c|c|c|c|c|}
\hline & Hypopharynx & Larynx & Oral cavity & Oropharynx & p-value \\
\hline $\begin{array}{l}\text { TVRR-T (\%) } \\
\text { [IQR] }\end{array}$ & $\begin{array}{l}41.1 \\
{[24.2,56.1]}\end{array}$ & $\begin{array}{l}41.1 \\
{[19.6,50.2]}\end{array}$ & $\begin{array}{l}44.0 \\
{[24.1,53.8]}\end{array}$ & $44.1[33.2,53.0]$ & 0.812 \\
\hline $\begin{array}{l}\text { TVRR-N (\%) } \\
\text { [IQR] }\end{array}$ & $\begin{array}{l}51.8 \\
{[27.9,64.0]}\end{array}$ & $\begin{array}{l}63.5 \\
{[53.5,73.3]}\end{array}$ & $40.6[7.9,59.0]$ & $59.8[45.1,70.5]$ & $0.019 *$ \\
\hline \multicolumn{6}{|l|}{ Disease status } \\
\hline $\begin{array}{l}\text { Never disease } \\
\text { free }\end{array}$ & $8(25.8)$ & $2(18.2)$ & $13(68.4)$ & $2(6.9)$ & $<0.001^{*}$ \\
\hline No recurrence & $16(51.6)$ & $5(45.5)$ & $4(21.1)$ & $13(44.8)$ & \\
\hline Recurrence & $7(22.6)$ & $4(36.4)$ & $2(10.5)$ & $14(48.3)$ & \\
\hline
\end{tabular}

\section{Outcome of definitive treatment and characteristic of recurrence status}

After definitive treatment, thirty-five $(25 / 90,27.8 \%)$ patients were never disease free, who tended to have higher T (T4b 52\%) and overall stage (stage IVB 60\%), lower tumor reduction rates (TVRR-T $41.1 \%$, and TVRR-N 43.4\%), and shorter median follow-up days (387), compared to other initial complete remission group (recurrence median follow-up days 1133 and no recurrence group 1827). Oral cavity comprised $52 \%$ in this group. (as shown in Table 3 ) 
Table 3

Patient characteristics grouped by disease status * $\mathrm{QQR}$, interquartile range; TVRR tumor volume reduction rate; TPF, docetaxel (Taxotere), cisplatin (Platinol), and fluorouracil.

\begin{tabular}{|c|c|c|c|c|}
\hline & $\begin{array}{l}\text { Never disease } \\
\text { free }\end{array}$ & No recurrence & Recurrence & p-value \\
\hline $\mathrm{n}$ & 25 & 38 & 27 & \\
\hline \multicolumn{5}{|l|}{ T category } \\
\hline 1 & $2(8.0)$ & 0 & 0 & $<0.001^{*}$ \\
\hline 2 & 0 & $15(39.5)$ & 5 (18.5) & \\
\hline 3 & $1(4.0)$ & 8 (21.1) & 8 (29.6) & \\
\hline $4 \mathrm{~A}$ & $9(36.0)$ & $7(18.4)$ & 9 (33.3) & \\
\hline 4B & $13(52.0)$ & $8(21.1)$ & $5(18.5)$ & \\
\hline \multicolumn{5}{|l|}{ N category } \\
\hline 0 & $1(4.0)$ & $4(10.5)$ & $6(22.2)$ & 0.310 \\
\hline 1 & 0 & 0 & $1(3.7)$ & \\
\hline $2 A$ & 0 & $1(2.6)$ & 0 & \\
\hline 2B & $8(32.0)$ & 15 (39.5) & $13(48.1)$ & \\
\hline $2 \mathrm{C}$ & $14(56.0)$ & $16(42.1)$ & $6(22.2)$ & \\
\hline 3 & $2(8.0)$ & $2(5.3)$ & $1(3.7)$ & \\
\hline \multicolumn{5}{|l|}{ Stage } \\
\hline 3 & 0 & $1(2.6)$ & $2(7.4)$ & $0.013^{*}$ \\
\hline $4 \mathrm{~A}$ & $10(40.0)$ & 28 (73.7) & $19(70.4)$ & \\
\hline 4B & $15(60.0)$ & $9(23.7)$ & $6(22.2)$ & \\
\hline \multicolumn{5}{|l|}{ Cancer site } \\
\hline Hypopharynx & $8(32.0)$ & $16(42.1)$ & $7(25.9)$ & $<0.001^{*}$ \\
\hline Larynx & $2(8.0)$ & $5(13.2)$ & $4(14.8)$ & \\
\hline Oral cavity & $13(52.0)$ & $4(10.5)$ & $2(7.4)$ & \\
\hline Oropharynx & $2(8.0)$ & $13(34.2)$ & $14(51.9)$ & \\
\hline $\begin{array}{l}\text { Follow-up days (median, } \\
\text { [IQR]) }\end{array}$ & $\begin{array}{l}387.0 \\
{[277.0,507.0]}\end{array}$ & $\begin{array}{l}1827.0 \\
{[1526.2,2090.8]}\end{array}$ & $\begin{array}{l}1133.0 \\
{[849.0,1898.0]}\end{array}$ & $<0.001^{*}$ \\
\hline $\begin{array}{l}\text { TVRR-T (\%) (median, } \\
\text { [IQR]) }\end{array}$ & $41.1[19.0,51.4]$ & $48.3[35.2,61.1]$ & $36.3[23.8,48.3]$ & $0.025^{\star}$ \\
\hline
\end{tabular}




\begin{tabular}{|lllll|}
\hline & $\begin{array}{l}\text { Never disease } \\
\text { free }\end{array}$ & No recurrence & Recurrence & p-value \\
\hline $\begin{array}{l}\text { TVRR-N (\%) (median, } \\
\text { [IQR]) }\end{array}$ & $43.4[5.3,59.7]$ & $51.8[31.5,66.7]$ & $60.3[49.6,70.4]$ & $0.008^{*}$ \\
\hline $\begin{array}{l}\text { TPF cycles (median, } \\
\text { [IQR]) }\end{array}$ & $3.0[3.0,3.0]$ & $3.0[2.5,3.0]$ & $3.0[2.6,3.0]$ & 0.703 \\
\hline Recur pattern & & & $3(11.1)$ & \\
\hline Distal Metastasis & $1(33.3)$ & & $22(81.5)$ & \\
\hline Locoregional Recurrence & $1(33.3)$ & $5(100.0)$ & $2(7.4)$ & \\
\hline Second Primary & $1(33.3)$ & & $001^{*}$ \\
\hline
\end{tabular}

Sixty-five $(65 / 90,72.2 \%)$ patients reached initial complete remission. The recurrence pattern in this group was $33.8 \%(n=22)$ with locoregional recurrence, $4.6 \%(n=3)$ with distal metastasis, $7.7 \%$ with second primary cancer $(n=5)$ and $3.1 \%(n=2)$ with both locoregional recurrence and second primary cancer combined. In following disease-free survival analysis, patients with second primary were censored at the date of second primary cancer diagnosis. There was no patient with distal metastases and locoregional recurrence combined.

\section{TVRR-T and RECIST: univariate and multivariate using Cox regression model}

In univariate Cox regression analysis, the TVRR-T as a continuous variable showed a significant difference for DFS (hazard ratio [HR] 0.77, 95\% confidence interval $(\mathrm{Cl}) 0.63$ to $0.96 ; \mathrm{P}=0.02$ ); otherwise, TVRR-N, age, IC dose (docetaxel), cancer sites, RECIST, completion of RT treatment, and concurrence with cisplatin-based chemotherapy as variables were not. In multivariate analysis, TVRR-T was also a significant prognostic factor for DFS (HR $0.77,95 \% \mathrm{Cl} 0.62$ to $0.97 ; \mathrm{P}=0.02$ ), with covariates of age, IC dosage, oral cavity cancer (or other primary sites). (Table 4) 
Table 4

Univariate and multivariate Cox regression analysis of the associations between prognostic factors and disease free survival (DFS) outcomes. *TVRR-T, tumor volume reduction rate of primary tumor; TVRR-N, tumor volume reduction rate of lymph node

\begin{tabular}{|lllll|}
\hline & Univariate analysis & \multicolumn{2}{l|}{ Multivariate analysis } \\
\hline & Hazard $(95 \% \mathrm{Cl})$ & $p$-value & Hazard $(95 \% \mathrm{Cl})$ & $p$-value \\
\hline TVRR-T & $0.77(0.63,0.96)$ & $0.02^{\star}$ & $0.77(0.62,0.97)$ & $0.02^{\star}$ \\
\hline TVRR-N & $1.17(0.96,1.42)$ & 0.120 & & \\
\hline RECIST & $1.31(0.62,2.76)$ & 0.470 & & \\
\hline Age & $0.84(0.53,1.38)$ & 0.500 & $1.00(0.57,1.77)$ & 1.00 \\
\hline IC dose (Docitaxel) & $1.26(0.67,2.40)$ & 0.470 & $1.15(0.55,2.40)$ & 0.70 \\
\hline Cancer sites & $0.93(0.22,3.92)$ & 0.920 & $0.86(0.18,4.00)$ & 0.840 \\
(Oral cavity vs non-oral cavity) & & & & \\
\hline Complete RT & $1.00(0.24,4.22)$ & 0.996 & & \\
\hline RT concurrent with cisplatin & $2.13(0.99,4.56)$ & 0.053 & & \\
\hline
\end{tabular}

\section{Cut-off point of the TVRR-T for OS and DSF}

For Kaplan-Meier survival analysis, we used a cutoff value of $50 \%$ for the TVRR-T to stratify those who reached initial complete remission $(n=65)$ into two groups: good responder $(n=23)$ and poor responder $(n=42)$, the DFS was significant higher with TVRR-T $\geq 50 \%$ group (log-rank test, $p=0.024)$. (Figure $3 A$ ) If all patients were considered, including those who had never been disease free, there was still significant higher DFS (log-rank test, $p=0.01)$ for good responder $(n=30)$, compared to poor responder $(n=60)$. (Figure 3B) There was also a trend of improved OS in good responder $(n=30)$, compare to poor responder $(n=60)$ (log-rank test, $p=0.069)$. (Figure 3C)

\section{Discussion}

With imaging improvement, volumetric method theoretically provided more accurate description for gross tumor. In other cancer sites, such as rectal cancer, the extent of tumor volume shrinkage is an established prognostic factor.[17]' [18] In small cell lung cancer, response volume also correlated to outcome of definitive RT.[19] In locally advanved nasopharyngeal cancer, a study found a cutoff point (12.6\%) of tumor volume reduction rate after neoadjuvant chemotherpay to serve as a prognositc value for disease control, including overall survival.[20] 
In HNSCC, lower intra-treatment SUVmax and lower nodal volume on PET/CT has association with improved outcome.[21] Metabolic tumor volume change under PET/CT after first IC cycle has been suggested as an early prognostic indicator of response for following (chemo)radiation.[22] However, the correlation between IC treatment response and following outcomes remains unclear.

In this study we found the retrospective data supporting that TVRR-T has correlation to following curative intent (chemo)radiotherapy. In good responders, $77 \%$ of patients had reached complete remission, and also reached a significant superior disease free survival compared to poor responders, while the one dimensional RECIST failed to show correlation to disease control.

As for laryngeal and hypopharyngeal cancer, patients could the benefit from IC to spare morbid surgeries and resulted in satisfactory disease control. Literature focusing on response after IC in HNSCC usually sorted patients into good and poor responders by various measurement, including RECIST or WHO. In some prospective studies, tumor volume reduction rate had taken the role to stratify HNSCC patients.[23]' [24] However, there was still no evidence that the response to IC can be used as the indicator of organ preservation[10]

In most larynx preservation prospective trials protocol, for poor responders, defined as stable to progression disease, the patients under go total laryngectomy for an non-inferior comparison to definitive (C)RT. $[8,9,10,25,26]$ Using our retrospective data, we had collected a curative intent cohort with same protocol after IC for all patients, both good and poor responders alike. Despite locally advanced in general, this cohort resulted in a superior DSF for good responders, reinforcing the rationale that good responders are suitable for organ preservation.

This study also revealed a discordant treatment response between primary tumors and involved lymph nodes in few patients. Some individuals had paradoxical responses to IC, that their primary tumor volume reduced but lymph nodes enlarged. Such finding is coherent with prognostic value that TVRR-T to DFS, while TVRR-N did not. This phenomenon had also been described in some immunotherapy studies, in which tumor shrinkage varied at primary and nodal sites, possibly due to different microenvironment.[27] For poor responders with progression disease, especially in nodal metastases, salvage surgical treatment such as neck lymph node dissection should be considered an option.

We also noticed an overall lower survival in our cohort compared to historical study. In Taiwan, unlike the Western population, patients with non-HPV oropharyngeal cancer still outnumbered the HPV-related counterpart, despite a rising trend in HPV-related group.[28] In our study cohort, up to $92.3 \%(\mathrm{~N}=12)$ were non-HPV-related oropharyngeal cancer, which may result in the poorer outcome, regarding historical study like RTOG 0129, in which study HPV+ and HPV-3-year locoregional control were $86 \%$ and 65\%.[29] With majority of patient with smoking (88.1\%) and p16-negative (92.3\%) risk factors in this cohort, an inferior outcome is understandable.

Other possible cause of inferior disease control in this cohort could be a considerable amount of oral cavity cancer. As a primarily surgical disease, they consisted of $21.1 \%$ in our study cohort. These patients 
reached an overall local control of $21 \%, 68 \%$ never free of disease, and OS of $25 \%$, a much worse treatment outcome compared to PARADIGM trial, in which $18 \%$ oral cavity cancer and $45 \%$ patients with non-oropharyneal cancer group yielded 3-year PFS 66\% [45-80, 95\% Cl], and OS 73\% [52-85, 95\% CI][30], non-inferior to oropharyngeal cancer.

Despite the suspicion of oral cavity may contribute to inferior outcome, multivariate Cox regression analysis revealed non-significant hazard to DFS, after adjusting age, IC dose, and oral cavity (versus non oral cavity) cancer as covariates.

In summary, our study showed that TVRR-T after IC is prognostic of DFS in LA-HNSCC patient. As therapeutic and prognostic indicator, combined with future radiomic features, may be a useful reference for clinical judgement.[31] To better justified this treatment response organ preservation paradigm, larger prospective trial is need. Future prospective study design concerning IC could also consider volumetric measurement for treatment response.

The retrospective nature of this study only select patients who are suitable for IC and resulted in a group of patients with a variety of different outcome and treatment modality. This unavoidable heterogeneity may have undermined the survival analysis.

We have chosen docetaxel to represent the intensity of IC dosage in multivariate Cox regression analysis, as in TPF regimen, cisplatin and docetaxel was usually given in 1:1 ratio.

In DFS analysis, we excluded patients who failed to reach initial complete remission, although DFS had remained significantly better for good responders even if never disease free were considered. We believe an initial disease free have better representation for the outcome of definitive treatment, while those with residual tumor could have consideration for surgery.

There were considerable amount of patients who failed to failed to complete definitive (C)RT courses, thirteen patients $(n=13 / 90,14 \%)$, in which eight of them $(n=8 / 13,61.5 \%)$ also failed to reach initial complete remission. After exclude the patients who failed to reach initial complete remission, the completion of RT was still not a significant hazard to DFS in univariate Cox regression analysis.

The dosage of CCRT was not analyzed this retrospective study, despite the there was no significant disease free survival between patients received RT alone and those received CCRT, due to the majority patients received RT alone and a variety cycles was given, possibly a reflection of patient's performance status. While oncologists usually encourage patient with better performance to receive CCRT, we assumed that IC dose and completion of RT course had sufficed to describe the tolerable intensity of the whole treatment course.

Studies for volumetric measure usually favor MRIs over CT images, for MRIs have better quality to delineate tumor. However, accessibility of CT make CT still be a reliable clinical tool. 


\section{Conclusion}

We found that the TVRR of primary tumor (TVRR-T) could predict the prognosis of patients with LAHNSCC. In univariate and multivariate analysis, we found that the TVRR-T is a significant prognostic factor for DFS. A cut-off point of $50 \%$ for the TVRR-T could indicate better DFS.

\section{Abbreviations}

Cl: confidence interval

CRT: chemoradiotherapy

DFS: disease-free survival (DFS)

GTV: gross tumor volume

GTV-N1: gross tumor volume of the involved nodes before IC

GTV-N2: gross tumor volume of the involved nodes at interim

GTV-T1: gross tumor volume of the primary tumor before IC

GTV-T2: gross tumor volume of the primary tumor at interim

HR: hazard ratio

IC: induction chemotherapy

LA-HNSCC: Locally advanced head and neck squamous cell carcinoma

$\mathrm{RT}$ : radiotherapy

TPF: docetaxel, cisplatin, 5-fluorouracil

TVRR: Tumor volume reduction rate

TVRR-N: Tumor volume reduction rate of the involved nodes

TVRR-T: Tumor volume reduction rate of the primary tumor

\section{Declarations}

\section{Ethical approval and consent to participate}

Data collection and analysis were approved by the institutional review board of China Medical University Hospital, Taichung, Taiwan. 


\section{Consent for publication}

Not applicable.

\section{Availability of supporting data}

The datasets used and/or analysed during the current study are available from the corresponding author on reasonable request.

\section{Competing interests}

The authors declare that they have no competing interests.

\section{Funding}

This study is supported by CMUH grant DMR-108-055.

\section{Authors' contributions}

TL analyzed and interpreted the patient data. $\mathrm{CH}$ was a major contributor in writing the manuscript. ML and FC provided clinical measurement of RECIST socre. All authors read and approved the final manuscript."

\section{Acknowledgements}

Not applicable.

\section{References}

1. Ghi MG, Paccagnella A, Ferrari D, Foa P, Alterio D, Codecà C, et al. Induction TPF followed by concomitant treatment versus concomitant treatment alone in locally advanced head and neck cancer. A phase II-III trial. Ann Oncol Off J Eur Soc Med Oncol 2017;28:2206-12. https://doi.org/10.1093/annonc/mdx299.

2. Cohen EEW, Karrison TG, Kocherginsky M, Mueller J, Egan R, Huang $\mathrm{CH}$, et al. Phase III randomized trial of induction chemotherapy in patients with N2 or N3 locally advanced head and neck cancer. J Clin Oncol Off J Am Soc Clin Oncol 2014;32:2735-43. https://doi.org/10.1200/JC0.2013.54.6309.

3. Haddad R, O'Neill A, Rabinowits G, Tishler R, Khuri F, Adkins D, et al. Induction chemotherapy followed by concurrent chemoradiotherapy (sequential chemoradiotherapy) versus concurrent chemoradiotherapy alone in locally advanced head and neck cancer (PARADIGM): a randomised phase 3 trial. Lancet Oncol 2013;14:257-64. https://doi.org/10.1016/S1470-2045(13)70011-1.

4. Hitt R, Grau JJ, López-Pousa A, Berrocal A, García-Girón C, Irigoyen A, et al. A randomized phase III trial comparing induction chemotherapy followed by chemoradiotherapy versus chemoradiotherapy 
alone as treatment of unresectable head and neck cancer. Ann Oncol 2014;25:216-25. https://doi.org/10.1093/annonc/mdt461.

5. Posner MR, Norris CM, Wirth LJ, Shin DM, Cullen KJ, Winquist EW, et al. Sequential therapy for the locally advanced larynx and hypopharynx cancer subgroup in TAX 324: survival, surgery, and organ preservation. Ann Oncol 2009;20:921-7. https://doi.org/10.1093/annonc/mdn752.

6. Ma J, Liu Y, Yang X, Zhang C, Zhang Z, Zhong L. Induction chemotherapy in patients with resectable head and neck squamous cell carcinoma: a meta-analysis. World J Surg Oncol 2013;11:67. https://doi.org/10.1186/1477-7819-11-67.

7. Lefebvre JL, Chevalier D, Luboinski B, Kirkpatrick A, Collette L, Sahmoud T. Larynx preservation in pyriform sinus cancer: preliminary results of a European Organization for Research and Treatment of Cancer phase III trial. EORTC Head and Neck Cancer Cooperative Group. J Natl Cancer Inst 1996;88:890-9.

8. Induction Chemotherapy plus Radiation Compared with Surgery plus Radiation in Patients with Advanced Laryngeal Cancer. N Engl J Med 1991;324:1685-90.

https://doi.org/10.1056/NEJM199106133242402.

9. Lefebvre J-L, Andry G, Chevalier D, Luboinski B, Collette L, Traissac L, et al. Laryngeal preservation with induction chemotherapy for hypopharyngeal squamous cell carcinoma: 10-year results of EORTC trial 24891. Ann Oncol Off J Eur Soc Med Oncol 2012;23:2708-14. https://doi.org/10.1093/annonc/mds065.

10. Janoray G, Pointreau Y, Garaud P, Chapet S, Alfonsi M, Sire C, et al. Long-term Results of a Multicenter Randomized Phase III Trial of Induction Chemotherapy With Cisplatin, 5-fluorouracil, \pm Docetaxel for Larynx Preservation. J Natl Cancer Inst 2016;108. https://doi.org/10.1093/jnci/djv368.

11. Lowe NM, Kershaw LE, Bernstein JM, Withey SB, Mais K, Homer JJ, et al. Pre-treatment tumour perfusion parameters and initial RECIST response do not predict long-term survival outcomes for patients with head and neck squamous cell carcinoma treated with induction chemotherapy. PLOS ONE 2018;13:e0194841. https://doi.org/10.1371/journal.pone.0194841.

12. Han YB, Oh SN, Choi MH, Lee SH, Jang HS, Lee MA, et al. Clinical impact of tumor volume reduction in rectal cancer following preoperative chemoradiation. Diagn Interv Imaging 2016;97:843-50. https://doi.org/10.1016/j.diii.2016.05.004.

13. Lee H, Ahn YC, Oh D, Nam H, Noh JM, Park SY. Tumor Volume Reduction Rate during Adaptive Radiation Therapy as a Prognosticator for Nasopharyngeal Cancer. Cancer Res Treat 2015;48:53745. https://doi.org/2016.48.2.537.

14. Knegjens JL, Hauptmann M, Pameijer FA, Balm AJ, Hoebers FJ, de Bois JA, et al. Tumor volume as prognostic factor in chemoradiation for advanced head and neck cancer. Head Neck 2011;33:37582. https://doi.org/10.1002/hed.21459.

15. Eisenhauer EA, Therasse P, Bogaerts J, Schwartz LH, Sargent D, Ford R, et al. New response evaluation criteria in solid tumours: revised RECIST guideline (version 1.1). Eur J Cancer Oxf Engl 1990 2009;45:228-47. https://doi.org/10.1016/j.ejca.2008.10.026. 
16. Hsieh C-Y, Lein M-Y, Yang S-N, Wang Y-C, Lin Y-J, Lin C-Y, et al. Dose-dense TPF induction chemotherapy for locally advanced head and neck cancer: a phase II study. BMC Cancer 2020;20:832. https://doi.org/10.1186/s12885-020-07347-6.

17. Shiraishi T, Sasaki T, Ikeda K, Tsukada Y, Nishizawa Y, Ito M. Predicting prognosis according to preoperative chemotherapy response in patients with locally advanced lower rectal cancer. BMC Cancer 2019;19:1222. https://doi.org/10.1186/s12885-019-6424-4.

18. Yeo S-G, Kim DY, Park JW, Oh JH, Kim SY, Chang HJ, et al. Tumor Volume Reduction Rate After Preoperative Chemoradiotherapy as a Prognostic Factor in Locally Advanced Rectal Cancer. Int J Radiat Oncol 2012;82:e193-9. https://doi.org/10.1016/j.ijrobp.2011.03.022.

19. Halvorsen TO, Herje M, Levin N, Bremnes RM, Brustugun OT, Fløtten $\emptyset$, et al. Tumour size reduction after the first chemotherapy-course and outcomes of chemoradiotherapy in limited disease small-cell lung cancer. Lung Cancer Amst Neth 2016;102:9-14.

https://doi.org/10.1016/j.lungcan.2016.10.003.

20. Yang H, Liu Y, Zhang R, Ye Y, Chen Q, Qin Q, et al. Prognostic value of the tumor volume reduction rate after neoadjuvant chemotherapy in patients with locoregional advanced nasopharyngeal carcinoma. Oral Oncol 2020;110:104897. https://doi.org/10.1016/j.oraloncology.2020.104897.

21. Mowery YM, Vergalasova I, Yoo DS, Das SK, Hara W, Brizel DM. Correlating Clinical Outcomes With Changes in Tumor Volume and 18F-FDG PET Characteristics During Radiation Therapy for Head and Neck Squamous Cell Carcinoma (HNSCC). Int J Radiat Oncol • Biol • Phys 2016;94:920. https://doi.org/10.1016/j.jijobp.2015.12.164.

22. Wong KH, Welsh L, Mcquaid D, Dunlop A, Murray I, Du Y, et al. Metabolic Tumor Volume Changes Measured by 18F-FDG-PET/CT After 1 Cycle of Induction Chemotherapy Is an Early Predictor of Radical Chemoradiation Therapy Outcome in Head and Neck Squamous Cell Carcinoma. Int J Radiat Oncol 2016;94:920-1. https://doi.org/10.1016/j.jijobp.2015.12.165.

23. Seiwert TY, Foster CC, Blair EA, Karrison TG, Agrawal N, Melotek JM, et al. OPTIMA: a phase II dose and volume de-escalation trial for human papillomavirus-positive oropharyngeal cancer. Ann Oncol Off J Eur Soc Med Oncol 2019;30:1673. https://doi.org/10.1093/annonc/mdz171.

24. Lefebvre JL, Pointreau Y, Rolland F, Alfonsi M, Baudoux A, Sire C, et al. Induction chemotherapy followed by either chemoradiotherapy or bioradiotherapy for larynx preservation: the TREMPLIN randomized phase II study. J Clin Oncol Off J Am Soc Clin Oncol 2013;31:853-9. https://doi.org/10.1200/JC0.2012.42.3988.

25. Forastiere AA, Zhang Q, Weber RS, Maor MH, Goepfert H, Pajak TF, et al. Long-term results of RTOG 91-11: a comparison of three nonsurgical treatment strategies to preserve the larynx in patients with locally advanced larynx cancer. J Clin Oncol Off J Am Soc Clin Oncol 2013;31:845-52. https://doi.org/10.1200/JC0.2012.43.6097.

26. Semrau S, Schmidt D, Lell M, Waldfahrer F, Lettmaier S, Kuwert T, et al. Results of chemoselection with short induction chemotherapy followed by chemoradiation or surgery in the treatment of 
functionally inoperable carcinomas of the pharynx and larynx. Oral Oncol 2013;49:454-60. https://doi.org/10.1016/j.oraloncology.2012.12.008.

27. Merlino DJ, Johnson JM, Tuluc M, Gargano S, Stapp R, Harshyne L, et al. Discordant Responses Between Primary Head and Neck Tumors and Nodal Metastases Treated With Neoadjuvant Nivolumab: Correlation of Radiographic and Pathologic Treatment Effect. Front Oncol 2020;10:566315. https://doi.org/10.3389/fonc.2020.566315.

28. Hwang T-Z, Hsiao J-R, Tsai C-R, Chang JS. Incidence trends of human papillomavirus-related head and neck cancer in Taiwan, 1995-2009: Human papillomavirus-related head and neck cancer in Taiwan. Int J Cancer 2015;137:395-408. https://doi.org/10.1002/ijc.29330.

29. Nguyen-Tan PF, Zhang Q, Ang KK, Weber RS, Rosenthal DI, Soulieres D, et al. Randomized Phase III Trial to Test Accelerated Versus Standard Fractionation in Combination With Concurrent Cisplatin for Head and Neck Carcinomas in the Radiation Therapy Oncology Group 0129 Trial: Long-Term Report of Efficacy and Toxicity. J Clin Oncol 2014;32:3858-67. https://doi.org/10.1200/JC0.2014.55.3925.

30. Haddad R, O'Neill A, Rabinowits G, Tishler R, Khuri F, Adkins D, et al. Induction chemotherapy followed by concurrent chemoradiotherapy (sequential chemoradiotherapy) versus concurrent chemoradiotherapy alone in locally advanced head and neck cancer (PARADIGM): a randomised phase 3 trial. Lancet Oncol 2013;14:257-64. https://doi.org/10.1016/S1470-2045(13)70011-1.

31. Agarwal JP, Sinha S, Goda JS, Joshi K, Mhatre R, Kannan S, et al. Tumor radiomic features complement clinico-radiological factors in predicting long-term local control and laryngectomy free survival in locally advanced laryngo-pharyngeal cancers. Br J Radiol 2020;93:20190857. https://doi.org/10.1259/bjr.20190857.

\section{Figures}

$1 \mathrm{~A}$

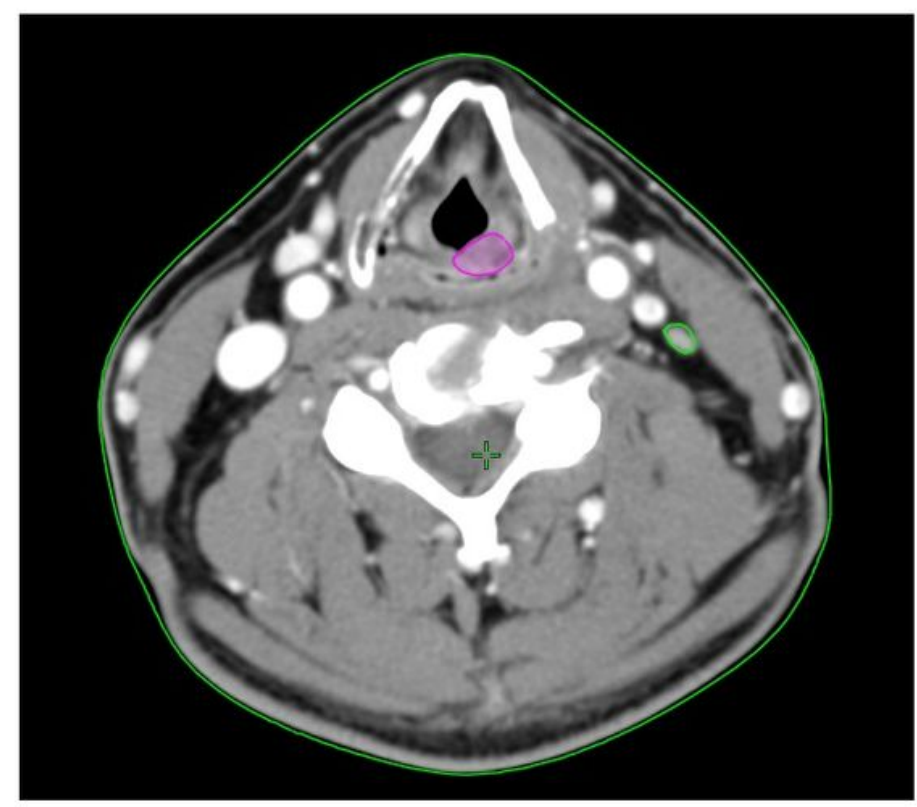

1B

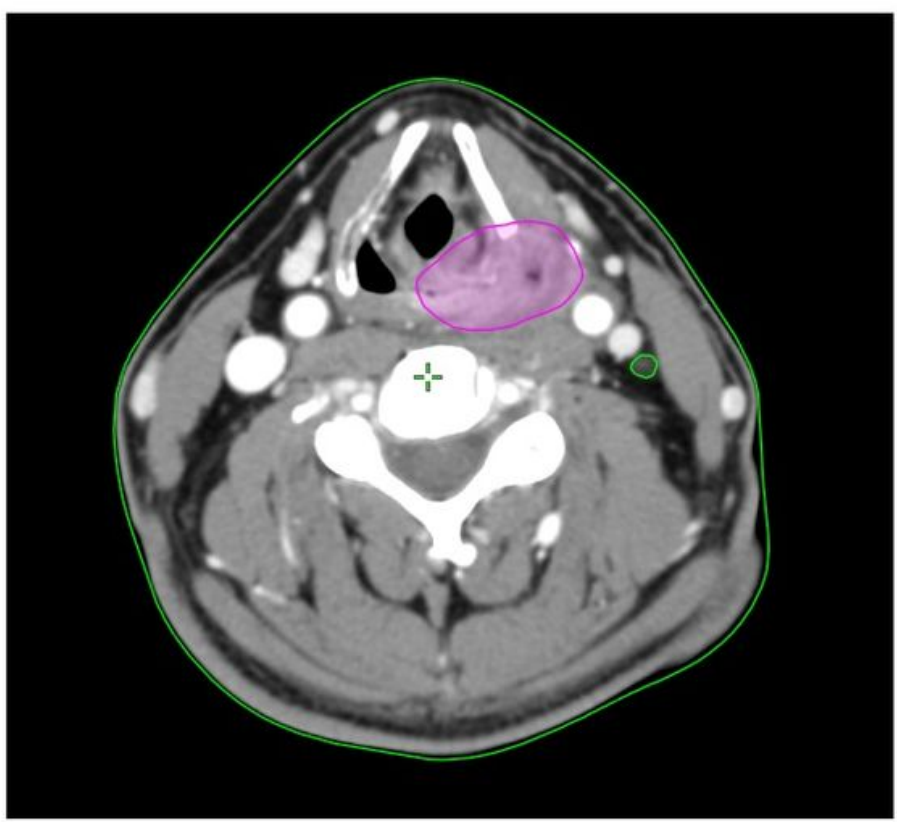


Figure 1

1A delineating gross tumor volume before IC on contrast-enhanced CT images, primary tumor designated as GTV-T1 (purple), and the involved nodes designated as GTV-N1 (green) 1B delineating gross tumor volume on interim CT, primary tumor designated as GTV-T2 (purple), and the involved nodes designated as GTV-N2 (green)

$2 \mathrm{~A}$

TVRR-T

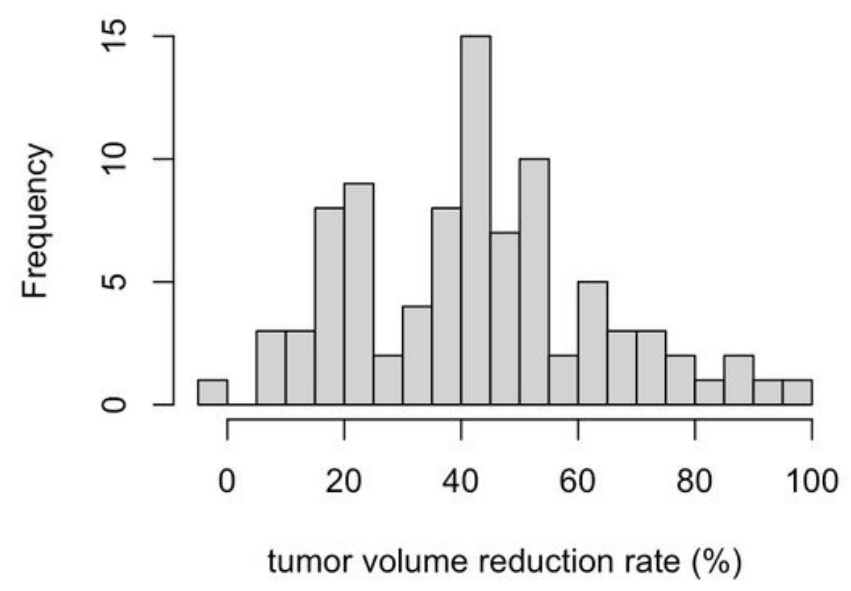

2B

\section{TVRR-N}

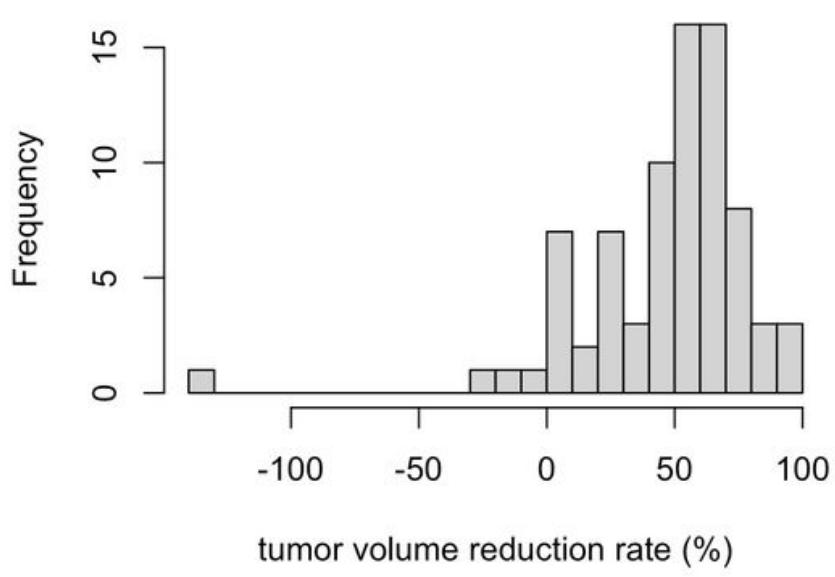

\section{Figure 2}

2A distribution of TVRR-T 2B distribution of TVRR-N 
$3 A$

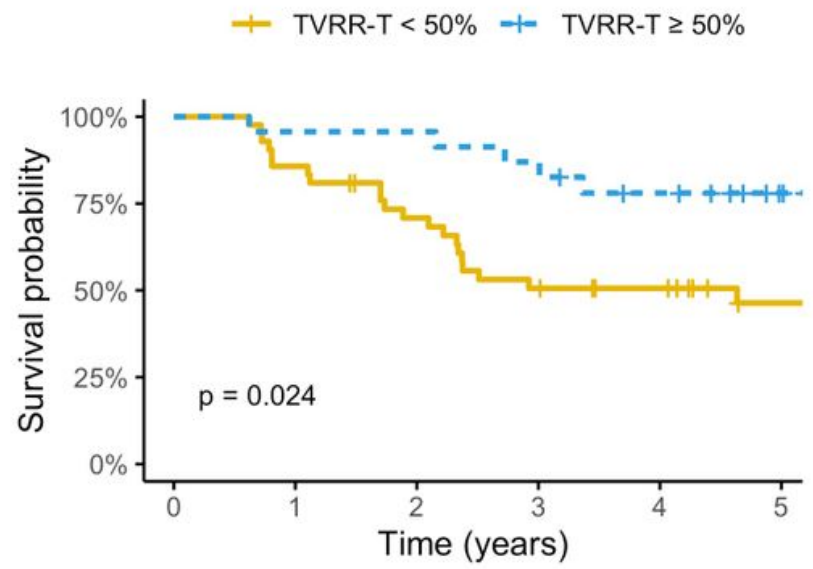

3B

+ TVRR-T $<50 \%+$ TVRR $-\mathrm{T} \geq 50 \%$

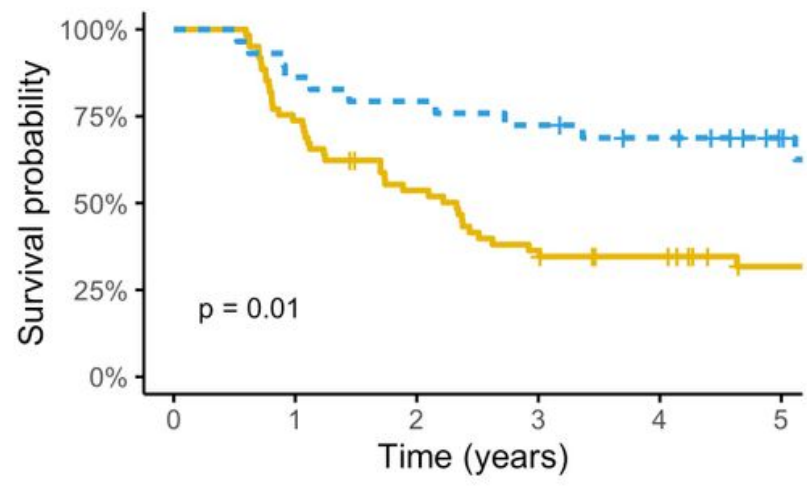

\section{$3 C$}

+ TVRR-T $<50 \%=$ TVRR-T $\geq 50 \%$

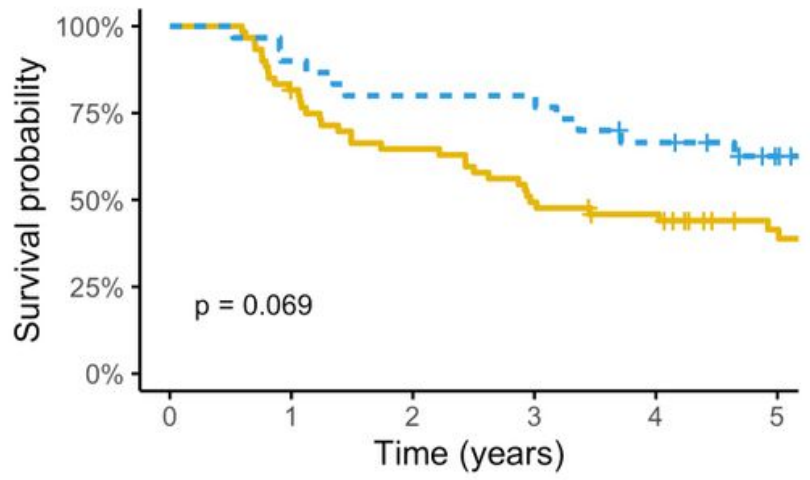

\section{Figure 3}

3A disease free survival by a cut-off point of $50 \%$ of TVRR-T. (only patients with initial complete remission were included $(n=65)$ ) 3B disease free survival by a cut-off point of $50 \%$ of TVRR-T. (All patients were included $(n=90)$ ) 3 C overall survival by a cut-off point of $50 \%$ of TVRR-T (All patients were included $(n=90))$ 